Original Article

\title{
POPULATION PHARMACOKINETICS OF 2-OXO-CLOPIDOGREL IN PATIENTS WITH ACUTE CORONARY SYNDROME
}

\author{
Valentina N. Nikolić ${ }^{1}$, Slobodan M. Janković ${ }^{2}$, Dragana Stokanović ${ }^{1}$, Sandra S. Konstantinović ${ }^{3}$, \\ Jelena B. Zvezdanović ${ }^{3}$, Nikola Stefanović ${ }^{4}$, Jelena Lilićs ${ }^{5}$, Svetlana R. Apostolović ${ }^{6,7}$, \\ Tatjana Jevtović-Stoimenov ${ }^{8}$, Jasmina R. Milovanović \\ ${ }^{1}$ Department of Pharmacology and Toxicology, University of Niš Faculty of Medicine, Niš, Serbia \\ ${ }^{2}$ Department of Pharmacology, University of Kragujevac Faculty of Medical Sciences, Kragujevac, Serbia \\ ${ }^{3}$ Department of Chemistry, University of Niš Faculty of Technology, Leskovac, Serbia \\ ${ }^{4}$ Department of Pharmacy, University of Niš Faculty of Medicine, Niš, Serbia \\ ${ }^{5}$ University of Nis Faculty of Medicine, Niš, Serbia \\ ${ }^{6}$ Department of Cardiology, University of Niš, Faculty of Medicine, Niš, Serbia \\ ${ }^{7}$ Clinic for Cardiovascular Diseases, Clinical Center Niš, Niš, Serbia \\ ${ }^{8}$ Department of Biochemistry, University of Nis Faculty of Medicine, Niš, Serbia
}

\begin{abstract}
The aim of the study was to develop a population pharmacokinetic (PK) model for clearance of 2-oxo-clopidogrel in patients with acute coronary syndrome (ACS). Population pharmacokinetic analysis was performed by using 72 plasma concentrations from the same number of patients (mean age of $60.82 \pm 10.76$ years; total body weight (TBW) of $73.63 \pm 9.67$ $\mathrm{kg}$ ) with ACS using non-linear mixed-effect modeling (NONMEM). Validation of the final PPK model was carried out through the bootstrap analysis with 200 runs and it was used to estimate the predictive performance of the pharmacokinetic model. The typical mean value for 2-oxo-clopidogrel clearance (CL), estimated by the base model (without covariates), in our population was $39.2 \mathrm{l} \mathrm{h-1}$.The value of aspartate transaminase and co-medication with digoxin were determinants of a derived population model. The final regression model for the clearance of 2-oxo-clopidogrel was the following: $C L\left(\mathrm{l}^{-1}\right)=$ $1.7+1.31 * A S T+115^{*}$ DIGOXIN. The derived PK model describes the clearance of 2-oxo-clopidogrel in patients with ACS, showing that the value of aspartate transaminase and co-medication with digoxin are the most important covariate. This finding will provide the basis for future PK studies.
\end{abstract}

Key words: 2-oxo-clopidogrel, acute coronary syndrome, population pharmacokinetics, clearance, Nonlinear mixed effects model (NONMEM).

\section{Introduction}

Clopidogrel, a second generation thienopyridine, is P2Y12 subtype of adenosine diphosphate (ADP) receptor antagonist. To date, a large number of conducted studies have shown clinical benefit of treatment with clopidogrel in addition to aspirin as dual antiplatelet therapy for acute coronary syndrome (ACS) and/or undergoing percutaneous coronary intervention (PCI) [1-3]. It is still cornerstone antiplatelet therapy for coronary heart disease despite some advantages of new $\mathrm{P} 2 \mathrm{Y} 12$ receptor antagonists such as prasugrel and ticagrelor $[4,5]$. The higher treatment cost of novel antiplatelet drugs, as well as its higher risk of major bleeding, maintained clopidogrel as first -line therapy option and extensively prescribed drug worldwide.

Clopidogrel is a prodrug, and its biotransformation by a 2-step, cytohrome $\mathrm{P}_{450}$ - dependent process, is requested for conversion to its active metabolite. Introduction of one oxygen atom into clopidogrel, and its conversion to 2-oxo-

Correspondence to: Valentina Nikolić, M.D., Ph.D.

Department of Pharmacology and Toxicology, University of Niš Faculty of Medicine, Niš, Serbia, Dr. Zoran Djindjić Blvd. 81, 18000 Niš, Serbia Phone: +381631045064

E-mail: valentina@medfak.ni.ac.rs

Received December $24^{\text {th }}, 2018$, Accepted December $26^{\text {th }}, 2018$ clopidogrel is the first step of its hepatic metabolism with contribution of CYP1A2, CYP2B6, and CYP2C19 by $35.8,19.4$ and $44 \%$, respectively [6]. In the next oxidation process, 2-oxo-clopidogrel is converted into the pharmacologically active metabolite R-130964 by CYP2B6 (32.9\%), CYP2C9 (6.76\%), CYP2C19 (20.6\%), and CYP3A4 (39.8\%) enzymes [7]. The genes encoding CYP3A4/5 and CYP2C19 are polymorphic and accountable in variability of clopidogrel pharmacokinetics. Based on the available information regarding a correlation between both pharmacokinetic parameters of clopidogrel and $\mathrm{H} 4$, active metabolite of clopidogrel, as well as the Cmax of the $\mathrm{H} 4$ isomer and platelet aggregation, the intestinal absorption of clopidogrel may be considered as rate-limiting process [6, 8]. Additionally, the latter observations allowed the prediction of pharmacodynamics response to clopidogrel using pharmacokinetic data on clopidogrel or 2-oxo-cxopidogrel. Furthermore, previous publications have suggested both active metabolite's instability and existance in the plasm for a short period $[6,9]$. In accordance with the previously mentioned, in this study we evaluated the clinical and demographic factors that influence 2oxo-clopidogrel clearance, supposing this is relevant for vicagrel, novel analog of clopidogrel and its further development in phase II/III studies [10]. 
The focus of our study was the evaluation PK variability of 2-oxo-clopidogrel in patients with acute coronary syndrome (ACS) using the population PK approach.

\section{Methods}

\section{Patient Data}

The investigation was performed at the Clinic of Cardiology, Clinical Center Niš, Serbia during three months (from February to May 2016) after obtaining permission of the Ethics Committee of the University of Nis, Faculty of Medicine. All patients were informed about the details related to the study protocol and were included after their written consent. The including criteria were: patients of both sexes older than 18 years, with diagnosis of acute coronary syndrome (ACS) with/without ST-elevation as confirmed by the cardiologists, using the electrocardiogram and the biochemical tests. The exclusion criteria for our study were: pregnant and lactating women, presence of mental disorders and patients' refusal to participate in the study.

Our study population consisted of 72 patients treated with clopidogrel in accordance with Institutional Review Board/Human Subjects Research Committee requirements. The dual antiplatelet therapy (acetylsalicylic acid and clopidogrel) was administered in all patients. Clopidogrel loading dose was $300 \mathrm{mg}$ or $600 \mathrm{mg}$ and it varied depending on the revascularization procedure (PCI or fibrinolytics) and patients' status. After that, clopidogrel was administered once daily, at the maintenance dose of $75 \mathrm{mg}$ or $150 \mathrm{mg}$. Besides that, all patients also received angiotensin-converting enzyme (ACE) inhibitors and other drugs presented in Table 1. This data and other clinical and demographic data of patients (ejection fraction (ER), their concomitant diseases, total body weight (TBW), age of patients and sex), were obtained from medical records, while data of life habits were recorded in a conversation with patients.

\section{Blood sampling and laboratory analysis}

The study protocol included taking four blood samples from all patients: two for the routine laboratory tests immediately after the admission of patients to hospital, and two blood samples after three days of starting therapy with clopidogrel for the patients' genotyping and measuring of the drug concentrations, respectively.

Oxoclopidogrel concentrations were measured from the serum samples at the steady-state concentrations using the ultrahigh-performance liquid chromatography with diode array detector-mass spectrometry analysis (UHPLC-DAD-MS). The UHPLC was carried out on a Dionex Ultimate 3000 UHPLC system equipped with a DAD-detector and also connected to LCQ Fleet Ion Trap Mass Spectrometer (Thermo Fisher Scientific, USA). The process of separations was performed on a Poroshell 120 EC-C18 column $(4.6 \times 50 \mathrm{~mm}, 2.7 \mu \mathrm{m}$; Agilent technology, USA) at room temperature $\left(25^{\circ} \mathrm{C}\right)$. The absorption was recorded on DAD-detector (with total spectral range between $200 \mathrm{~nm}$ and $800 \mathrm{~nm}$ ), set at three detection wavelengths of 240, 220 and 300nm, simultaneously. Mass spectrometric analysis was performed using an LCQ 3D-ion trap mass spectrometer with electrospray ionization (ESI) in positive ion mode. MSspectra were acquired by full range acquisition of $\mathrm{m} / \mathrm{z}$ 300-500. For fragmentation study (MS/MS), a data dependent scan was performed by deploying the collisioninduced dissociation at $25 \mathrm{eV}$. The range of the linearity for oxoclopidogrel was ... with the lowest the limit of detection and quantification of serum concentration of oxoclopidogrel was $0.5 \mathrm{ng} / \mathrm{mL}$ and $50.0 \mathrm{ng} / \mathrm{mL}$ respectively. All the serum samples for this type of the analysis were obtained in Cmax concentrations, two hours after oral administration of morning dose of clopidogrel.

The patients' genotyping analysis was included before isolating manually the genomic DNA from the whole blood leukocytes and the following small nuclear polymorphisms (SNPs) which was determined by using the PCR (polymerase chain reaction) method: ABCB1 C34335T (rs1045642), CYP2C19*2 (rs4244285) and *17 (rs12248560), as well as CYP2C9*2 (rs1799853). The commercial mix KAPA2G Readymix (KAPA2G ReadyMix FastHotStart; Kappa Biosystems, Boston, MA, USA), the reaction mixture with specific primers were used for SNPs detections. For detection of gene polymorphism of ABCB1 C3435T were used primers $C\left(5^{\prime}-G G T G T C A\right.$ CAGGAAGAGATC-3'), (5'-CAGCCGGGTATAGTCA CAGGAAGATATT $\left.-3^{\prime}\right)$ and the reverse $\left(5^{\prime}-G G C C A G A\right.$ $G A G G C T G C C A C A T-3^{\prime}$ ), for the detection of gene polymorphism of $C Y P 2 C 19 * 2$ primers were used the forward $\left(5^{\prime}-A A T T A C A A C C A G A G C T T G G C-3^{\prime}\right)$, the reverse $\left(5^{\prime}-T A T C A C T T T C C A T A A A A G C A A G^{-} 3^{\prime}\right)$, for the recorded of gene polymorphism of $C Y P 2 C 19 * 17$ used the forward $\left(5^{\prime}-G C C C T T A G C A C C A A A T T C T C-3^{\prime}\right)$ and the reverse $\left(5^{\prime}-A T T T A A C C C C C T A A A A A A A C A C G^{-} 3^{\prime}\right)$ and the end for the detection of $\boldsymbol{C Y P 2 C} 9 * 2$ gene polymorphism was used the forward $\left(5^{\prime}-\right.$ GTATTTTGGCCTGA $\left.A A C C C A T A-3{ }^{\prime}\right)$ and the reverse $\left(5^{\prime}-G G C C T T G G T T\right.$ TTTCTCAACTC $-3^{\prime}$ ). The reaction condition consisted of the initiation at $95^{\circ} \mathrm{C}$ for 2 minutes followed by different number of cycles. In the case of ABCB1 no restriction enzyme was used, since the primers were allele specific. SNPs determination was performed after vertical electrophoresis in $8 \%$ polyacrylamide gel (ABCB1 C3435T and CYP2C19*2) or horizontal electrophoresis in $2 \%$ agarose gel (CYP2C19*17 and CYP2C9*2).

\section{Pharmacokinetic analysis}

For population pharmacokinetics (PPK) analysis of oxoclopidogrel and the estimates of its pharmacokinetics parameters (PK) of the target population, we applied the NONMEM software (version 7.3.0.) (Icon Development Solutions, USA) with ADVAN 1 subroutine which well describes a one-compartment model without absorption [11]. This model has given the best estimate of the main PK parameters of oxoclopidogrel, the apparent oral clearance $(\mathrm{CL} / \mathrm{F})$ and its inter-individual and residual (intraindividual) variability. The choice of appropriate subroutine was based on the literature data of clopidogrel and 
oxoclopidogrel pharmacokinetics and testing of different PPK models (using the lowest value of the minimum of objective function (MOF) as the mean statistical criteria between the tested models). In this step, with the aim to form the base PPK model of investigated drug, we also analyzed various models errors for the estimation of variability, using an exponential, additive, proportional and combined model errors. The parent drug, clopidogrel was administered orally in all patients and the influence of oral bioavailability $(\mathrm{F})$ was not considered in the analysis. The base PPK model of oxoclopidogrel was built using the collected data of 72 patients with ADVAN1 subroutine from the software library (without tested covariate).

Covariate of interest for the PPK analysis of oxoclopidogrel were the following: total body weight, age, sex, total daily dose of clopidogrel, ejection fraction, cholesterol and triglyceride levels, red blood cells (RBC) count, creatinine clearance (calculated for each patient using the Cockcroft-Gault equation), aspartate transaminase (AST) and alanine transaminase (ALT), ABCB1 and CYP2C9 genotypes, CYP2C19 phenotype, concomitant disease as the presence of diabetes mellitus (DM) type 2, life habits such as smoking status of patient and co-medication with other drugs: beta-blockers, diuretics, spironolactone, amlodipine, amiodarone, digoxin, pantoprazole, sulphonylureas and statins (atorvastatine, rosuvastatine and simvastatine). The influence of 25 covariates on the pharmacokinetic disposition of oxoclopidogrel, were analyzed through the univariate regression models. This process consisted of adding only one of tested covariate in the base model (in a linear or nonlinear way), and then, its statistical significance was assessed on the reduction in the MOF value between this model and the base PPK model. The MOF is defined as 2loglikelihood and, therefore, its required reduction was at least $6.63(\mathrm{p}<0.01, \mathrm{df}=1)$. As the results of this complex process, we recorded all covariate with the significant influences on the PK parameters of oxoclopidogrel, and after that, were added in the full model, simultaneously. Further, the analysis was performed in the opposite manner, removing each individual covariate from the full model and noting the differences in the MOF value. In this process of backward removal, the main statistical criteria was stronger, with increasing of the MOF values by $\geq 10.83$ $(p<0.001, d f=1)$ [12]. Thus, the final PPK model of oxoclopidogrel consisted of only those covariate which satisfied both approach selection processed (forward addition and backward removal), suggesting their particular influence on pharmacokinetics of the investigated drug. Integral part of this analysis was a graphic inspection of data fitting between predicted, population values of concentration versus obtained, measured concentrations of oxoclopidogrel, which was obligatory conducted during all phases.

Validation of the final PPK model was carried out through the bootstrap analysis with 200 runs. This type of the internal validation was recommended for a small number of samples per patient by the Guidance for Industry Population Pharmacokinetics, FDA, for the estimation of the stability and predictive performances of the final PPK model [13]. Values of PK parameters and its variability from the bootsrap analysis were compared with the values from NONMEM analysis and if similar, that indicated a good predictive performance of the derived PPK model.

\section{Results}

The study population consisted of 72 patients of both sexes (28 female and 44 male) in order to assess the mean population value of the clearance of oxoclopidogrel, as the main metabolite of clopidogrel. The range of patients age was 37 to 85 years, including middle-age to elderly patients, with the average value of

Table 1 Respondent's characteristics (demographic, biochemical, genetic and clinical data)

\begin{tabular}{|c|c|c|}
\hline Characteristics of population & $\begin{array}{c}\text { Investigated set } \\
\text { (mean values } \\
\pm \mathrm{SD}^{*} \text { ) }\end{array}$ & $\begin{array}{c}\text { Range of } \\
\text { investigated } \\
\text { set }\end{array}$ \\
\hline Number of patients & 72 & \\
\hline Number of observations & 72 & \\
\hline Gender (male/female) & $44 / 28$ & \\
\hline TBW $(\mathrm{kg})$ & $73.63 \pm 9.67$ & $55-106$ \\
\hline Age (years) & $60.82 \pm 10.76$ & $37-85$ \\
\hline $\begin{array}{l}\text { Clopidogrel daily dose } \\
\text { (mg/day) }\end{array}$ & \pm 24.98 & $75-150$ \\
\hline $\begin{array}{l}\text { Oxoclopidogrel plasma } \\
\text { concentration }(\mathrm{mg} / \mathrm{l})\end{array}$ & $0.29 . \pm 0.39$ & $\begin{array}{r}0.0008- \\
1.7309\end{array}$ \\
\hline ABCB1 genotype: & 72 & \\
\hline$-\mathrm{CC}$ & -19 & \\
\hline$-\mathrm{CT}$ & -34 & \\
\hline - TT & -19 & \\
\hline CYP2C19 phenotype: & 72 & \\
\hline - PM & -4 & \\
\hline$-\mathrm{IM}$ & -19 & \\
\hline$-\mathrm{EM}$ & -25 & \\
\hline - URM & -24 & \\
\hline CYP2C9 genotype: & 72 & \\
\hline$-\mathrm{CC}$ & -56 & \\
\hline$-\mathrm{CT}$ & -15 & \\
\hline$-\mathrm{TT}$ & -1 & \\
\hline Ejection fractions $(\%)$ & $51.32 \pm 12.27$ & 28-79 \\
\hline Cholesterol levels (mmol/l) & $5.52 \pm 1.35$ & $2.95-10.87$ \\
\hline Triglyceride levels (mmol/l) & $2.19 \pm 3.85$ & $0.14-33$ \\
\hline RBC counts $\left(10^{12} / 1\right)$ & $4.66 \pm 0.68$ & $3.7-6.12$ \\
\hline $\operatorname{AST}(\mathrm{U} / \mathrm{l})$ & $117.21 \pm 169.81$ & $10.2-930$ \\
\hline $\operatorname{ALT}(\mathrm{U} / \mathrm{l})$ & $34.20 \pm 26.57$ & $1.27-146.7$ \\
\hline Creatinine clearance $\left(1 \mathrm{~h}^{-1}\right)$ & $4.38 \pm 1.47$ & $1.28-7.23$ \\
\hline Diabetes mellitus & 19 & \\
\hline Smokers & 24 & \\
\hline \multicolumn{3}{|l|}{ Co-medications with: } \\
\hline - Pantoprazole & -58 & \\
\hline - Beta blockers & -49 & \\
\hline - Diuretics & -21 & \\
\hline - Spironolactone & -14 & \\
\hline - Amlodipine & -12 & \\
\hline - Amiodarone & -8 & \\
\hline - Digoxin & -8 & \\
\hline - Sulphonylureas & -4 & \\
\hline - Statins: & -69 & \\
\hline - Atorvastatine & -60 & \\
\hline - Rosuvastatine & -2 & \\
\hline - Simvastatine & -7 & \\
\hline
\end{tabular}


body weight of $74 \mathrm{~kg}$. Clopidogrel tablets were routinely administered orally, once daily at the dose of $75 \mathrm{mg}$ $(\mathrm{n}=63,87.5 \%)$ or $150 \mathrm{mg}(\mathrm{n}=9,12.5 \%)$. The presence of DM type 2 was showed as the most common concomitant disease $(n=19,26.39 \%)$, while almost a third of the population were active smokers $(n=24,33.33 \%)$. In terms of co-medications with other drugs, three groups were administered most frequently: statins $(95.83 \%)$ as the drugs that reduce cholesterol levels (atorvastatine $(83.33 \%)$, rosuvastatine $(2.78 \%)$ and simvastatine $(9.72 \%))$, the gastroprotective therapy with the proton pump inhibitors (PPIs) (pantoprasole (80.56\%)) and beta blockers (BBs) $(68.06 \%)$. The other co-administered drugs were: diuretics $(29.17 \%)$, spironolactone (19.44\%), amlodipine (16.67\%), amiodarone (11.11\%), digoxin $(11.11 \%)$ and sulfonylurea derivatives $(5.56 \%)$.
The average serum concentration of oxoclopidogrel was $0.29 \pm 0.39$ followed with a wide range from 0.0008 to $1.730 \mathrm{mg}$ per liter in the population. Overall, demographic data, biochemical, genetic and clinical data of the respondents are presented in Table 1 .

The mean population value of oxoclopidogrel clearance without examining the effects of different covariate was 39.2 liters per hour in the base model. This analysis was carried out using one compartmental model with no absorption from NONMEM software, since the active metabolite was the objective of our investigation. Further, the process of forward selection was conducted in order to assess the influence of each individual factor on pharmacokinetics disposition of the drug. The values of MOF, evaluated by univariate models which examined the effects of separate factors on oxoclopidogrel clearance, are shown

Table 2 Values of MOF for the base model and univariate regression models of examined covariates with their statistical significance in the process of building of the full PPK model

\begin{tabular}{|c|c|c|}
\hline Clearance models & Minimum of objective function & p-value \\
\hline \multicolumn{3}{|l|}{ BASE MODEL } \\
\hline $\mathrm{CL}=\theta_{1} * \operatorname{EXP}(\mathrm{ETA}(1))$ & 1047.867 & \\
\hline \multicolumn{3}{|l|}{ UNIVARIATE REGRESSION MODELS } \\
\hline $\mathrm{CL}=\theta_{1} * \operatorname{EXP}(\operatorname{ETA}(1))+\theta_{2} * \mathrm{AGE}$ & 1030.711 & $<0.01$ \\
\hline $\mathrm{CL}=\theta_{1} * \operatorname{EXP}(\operatorname{ETA}(1))+\theta_{3} * \mathrm{TBW}$ & 1046.725 & $>0.01$ \\
\hline $\mathrm{CL}=\theta_{1} * \operatorname{EXP}(\operatorname{ETA}(1))+\theta_{4} * \mathrm{SEX}$ & 1047.867 & $>0.01$ \\
\hline $\mathrm{CL}=\theta_{1} * \operatorname{EXP}(\operatorname{ETA}(1))+\theta_{5} * \mathrm{DD}$ & 1047.108 & $>0.01$ \\
\hline $\mathrm{CL}=\theta_{1} * \operatorname{EXP}(\operatorname{ETA}(1))+\theta_{6} * \mathrm{ABCB} 1$ & 1046.007 & $>0.01$ \\
\hline $\mathrm{CL}=\theta_{1} * \operatorname{EXP}(\operatorname{ETA}(1))+\theta_{7} * \mathrm{CYP} 2 \mathrm{C} 19$ genotype & 1046.103 & $>0.01$ \\
\hline $\mathrm{CL}=\theta_{1} * \operatorname{EXP}(\operatorname{ETA}(1))+\theta_{8} * \mathrm{CYP} 2 \mathrm{C} 9$ genotype & 1046.477 & $>0.01$ \\
\hline $\mathrm{CL}=\theta_{1} * \operatorname{EXP}(\operatorname{ETA}(1))+\theta_{9} * \mathrm{EF}$ & 1047.001 & $>0.01$ \\
\hline $\mathrm{CL}=\theta_{1} * \operatorname{EXP}(\operatorname{ETA}(1))+\theta_{10} * \mathrm{CHOL}$ & 1031.930 & $<0.01$ \\
\hline $\mathrm{CL}=\theta_{1} * \operatorname{EXP}(\operatorname{ETA}(1))+\theta_{11} * \mathrm{TGL}$ & 1047.449 & $>0.01$ \\
\hline $\mathrm{CL}=\theta_{1} * \operatorname{EXP}(\operatorname{ETA}(1))+\theta_{12} * \mathrm{RBC}$ & 1047.867 & $>0.01$ \\
\hline $\mathrm{CL}=\theta_{1} * \operatorname{EXP}(\operatorname{ETA}(1))+\theta_{13} * \mathrm{AST}$ & 990.892 & $<0.01$ \\
\hline $\mathrm{CL}=\theta_{1} * \operatorname{EXP}(\operatorname{ETA}(1))+\theta_{14} * \mathrm{ALT}$ & 1047.866 & $>0.01$ \\
\hline $\mathrm{CL}=\theta_{1} * \operatorname{EXP}(\operatorname{ETA}(1))+\theta_{15} * \mathrm{CLcr}$ & 1047.138 & $>0.01$ \\
\hline $\mathrm{CL}=\theta_{1} * \operatorname{EXP}(\operatorname{ETA}(1))+\theta_{16} * \mathrm{DM}$ & 1047.867 & $>0.01$ \\
\hline $\mathrm{CL}=\theta_{1} * \operatorname{EXP}(\operatorname{ETA}(1))+\theta_{17} * \mathrm{TOB}$ & 1047.524 & $>0.01$ \\
\hline $\mathrm{CL}=\theta_{1} * \operatorname{EXP}(\operatorname{ETA}(1))+\theta_{18} * \mathrm{PANT}$ & 1047.424 & $>0.01$ \\
\hline $\mathrm{CL}=\theta_{1} * \operatorname{EXP}(\operatorname{ETA}(1))+\theta_{19} * \mathrm{BB}$ & 1047.867 & $>0.01$ \\
\hline $\mathrm{CL}=\theta_{1} * \operatorname{EXP}(\operatorname{ETA}(1))+\theta_{20} * \mathrm{DIU}$ & 1047.867 & $>0.01$ \\
\hline $\mathrm{CL}=\theta_{1} * \operatorname{EXP}(\operatorname{ETA}(1))+\theta_{21} * \mathrm{SPI}$ & 1047.860 & $>0.01$ \\
\hline $\mathrm{CL}=\theta_{1} * \operatorname{EXP}(\operatorname{ETA}(1))+\theta_{22} * \mathrm{AML}$ & 1047.867 & $>0.01$ \\
\hline $\mathrm{CL}=\theta_{1} * \operatorname{EXP}(\operatorname{ETA}(1))+\theta_{23} * \mathrm{AMI}$ & 1040.078 & $<0.01$ \\
\hline $\mathrm{CL}=\theta_{1} * \operatorname{EXP}(\operatorname{ETA}(1))+\theta_{24} * \mathrm{STAT}$ & 1047.867 & $>0.01$ \\
\hline $\mathrm{CL}=\theta_{1} * \operatorname{EXP}(\operatorname{ETA}(1))+\theta_{25} * \mathrm{DIG}$ & 1035.918 & $<0.01$ \\
\hline $\mathrm{CL}=\theta_{1} * \operatorname{EXP}(\operatorname{ETA}(1))+\theta_{26} * \mathrm{SUL}$ & 1047.867 & $>0.01$ \\
\hline \\
\hline \multirow{2}{*}{\multicolumn{3}{|c|}{$\begin{array}{l}\mathrm{CL}=\theta_{1} * \mathrm{EXP}(\mathrm{ETA}(1))+0.0000000845 * \mathrm{AGE} \\
+0.000000717 * \mathrm{CHOL}+1.31 * \mathrm{AST}+0.00000101 * \mathrm{AMI}+115 * \mathrm{DIG}\end{array}$}} \\
\hline & & \\
\hline \multicolumn{3}{|c|}{ 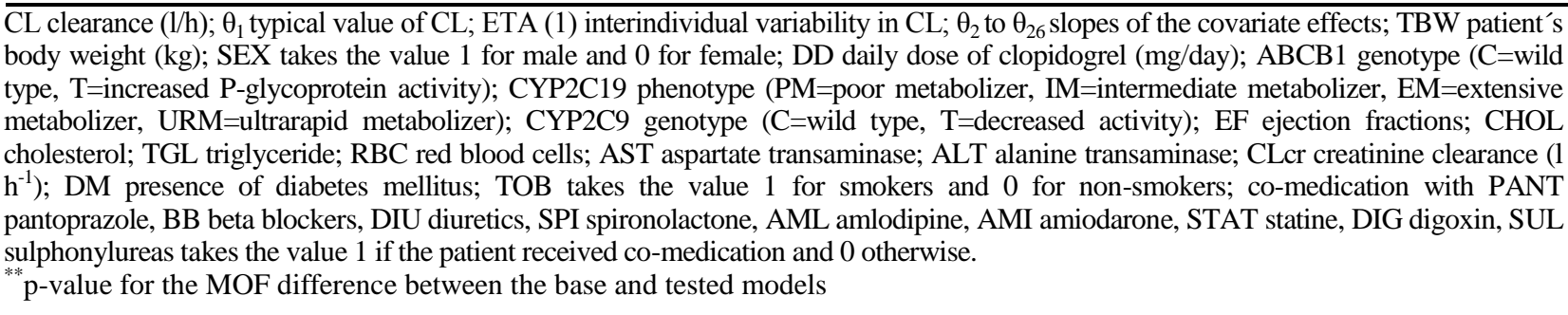 } \\
\hline
\end{tabular}


in Table 2. Required statistical significance (for $p<0.001$ ) in this step was the minimal difference in the MOF values of 6.63 between the base and a single regression model.

Thus, the full model consisted of the following covariates: age, cholesterol level, aspartate transaminase and co-medications with amiodarone and digoxin. Its effects on clearance of oxoclopidogrel had to be confirmed by the backward removal process with the strong statistical requirements (difference in $\mathrm{MOF} \geq 10.83$ for $\mathrm{p}<0.001$ ). In the next table, marked as Table 3, we presented this process which resulted in the confirmation of two covariates with significant influence on the apparent clearance of oxoclopidogrel and its variability. These were the value of aspartate transaminase and co-medication with digoxin in the target population, described in the form of the equation as:

$$
\mathrm{CL}\left(\mathrm{lh}^{-1}\right)=1.7+1.31 * \underline{\mathrm{AST}}+115 * \text { DIGOXIN }
$$

Table 3 The process of backward removal of covariate from a full PPK model of the clearance of oxoclopidogrel

\begin{tabular}{lcc}
\hline Covariates & $\begin{array}{c}\text { Difference in minimum } \\
\text { objective function }\end{array}$ & p-value \\
\hline Age & 1.798 & $>0.001$ \\
Cholesterol & 1.557 & $>0.001$ \\
AST & 50.084 & $<\mathbf{0 . 0 0 1}$ \\
Amiodarone & 0.969 & $>0.001$ \\
Digoxin & 17.162 & $<\mathbf{0 . 0 0 1}$ \\
p-value for the MOF difference between the base and tested \\
models
\end{tabular}

During the PPK analysis, the value of MOF was reduced by 61.924 units from the base to the final model. Furthermore, both inter-individual and residual variability (expressed as coefficient of variation) were $31.18 \%$ and $59.72 \%$ in the base model and were reduced to $16.01 \%$ and $41.51 \%$ in the final model, respectively. Much better correlation between measured oxoclopidogrel concentrations versus its population, predicted concentrations $(\mathrm{ng} / \mathrm{ml})$ in the final model is shown in Figure 1. The estimates of the apparent clearance of oxoclopidogrel, both investigated variability, and also the effects of aspartate transaminase and comedication with digoxin, are confirmed by the bootstrap analysis indicating a good precision and the stability of the final model (Table 4).

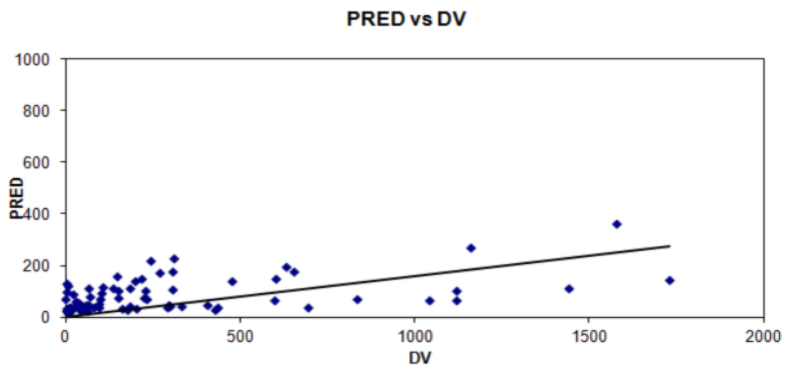

Fig. 1 Scatter-plot of predicted serum oxoclopidogrel concentrations (PRED) versus its measured serum concentrations (DV) expressed as $\mathrm{ng} / \mathrm{ml}$ in the final model.

\section{Discussion}

In the present study we developed and used a population pharmacokinetic model for the clearance of 2-oxoclopidogrel in routinely treated Serbian patients with ACS. We observed that the typical mean value for 2oxo-clopidogrel clearance, estimated by the base model (without covariates) in our population was $39.2 \mathrm{l} \mathrm{h}^{-1}$. Also, we noted large interindividual and residual variabilities in this phase.

Another potential source of pharmacokinetics variance of 2-oxo-clopidogrel is metabolic activity of CYP enzyme, especially the activity of CYP2C19 and CYP3A4 isoforms. The hepatic metabolism of 2-oxoclopidogrel involves dominantly CYP219 and 3A4 isoforms, with 20.6 and $39,8 \%$ of contribution, respectively [7]. The interindividual variability in the enzyme activity is partially genetically determined. Among genetic factors, the impact of the following potential covariates was evaluated: CYP2C19*2, CYP2C $19 * 17$, and ABCB1 3435 TT genotype. Our findings showed that CYP2C19 genotypes did not influence the clearance of 2-oxo-clopidogrel. Additionally, clearance of 2oxo-clopidogrel is not altered by ABCB1 3435 TT genotype. Future studies are required to verify these results, especially due to small sample size. The latter fact is an obvious limitation of this study, as well as only one sample per patient. Another PK analyses available in the literature are focused on the kinetics of inactive carboxylic acid metabolite $[14,15]$ or the $\mathrm{H} 4$ isomer which has the antiplatelet activity [16] and to the best of our knowledge no studies are available dealing with 2 oxoclopidogrel kinetics.

Table 4 Parameter estimates in the final model of oxoclopidogrel

\begin{tabular}{lcccccc}
\hline Parameter & \multicolumn{3}{c}{ NONMEM } & \multicolumn{3}{c}{ Bootstrap Analysis } \\
\cline { 2 - 7 } & Estimate & $95 \% \mathrm{CI}^{*}$ & Estimate & $95 \% \mathrm{CI}^{\sharp}$ \\
\hline $\mathrm{CL} / \mathrm{F}(\mathrm{l} / \mathrm{h})$ & 1.7 & $1.17-2.23$ & 1.66 & 1.05 & - & 2.27 \\
$\mathrm{AST}$ & 1.31 & $0.902-1.718$ & 1.40 & $0.907-1.893$ \\
DIGOXIN & 115.00 & 86.46 & -143.54 & 119.00 & 88.65 & -149.35 \\
Interindividual variance of CL $-\omega^{2} \mathrm{CL}$ & 0.0253 & $0.0154-0.0352$ & 0.0261 & $0.0141-0.0381$ \\
Residual variance $-\sigma^{2}$ (exponential) & 0.159 & $0.055-0.263$ & 0.162 & $0.065-0.259$ \\
\hline
\end{tabular}

* (Estimate) $\pm 1.96 \mathrm{x}$ (standard error of the estimate)

$\$ 2.5$ th and $97.5^{\text {th }}$ percentile of the ranked bootstrap parameter estimates 
Supposing the possibility that concomitant administration of drugs which share the same CYP450 metabolizing isoenzyme may alter the systemic exposure of 2-oxoclopidogrel, it was expected that any of them would have some influence on 2-oxo-clopidogrel. However, none of the drugs that are at least partially metabolized by CYP2C19 and 3A4 isoenzymes, influenced the clearance of 2-oxo-clopidogrel significantly. This could be explained by the relative contribution of additional CYP enzymes on 2-oxo-clopidogrel kinetics.

We tested the influence of 25 covariates on the pharmacokinetic disposition of 2-oxo-clopidogrel. In our final model, the only important factors influencing 2-oxoclopidogrel clearance, from among the covariates tested, were the value of aspartate transaminase and co-medication with digoxin. Previous publications have suggested that both drugs (clopidogrel and digoxin) are substrates of P-glycoprotein (P-gp), but the coadministration of clopidogrel with digoxin did not impact the pharmacokinetics of clopidogrel [17]. However, our results clearly show that 2-oxo-clopidogrel CL is notably increased when digoxin is added to therapy. This was unexpected and the mechanism by which digoxin increases CL of 2-oxoclopidogrel remains obscure.

\section{References}

1. Buonamici P, Marcucci R, Migliorini A, et al. Impact of platelet reactivity after clopidogrel administration on drug-eluting stent thrombosis. J Am Coll Cardiol 2007; 49:2312-2317.

2. Hochholzer W, Trenk D, Bestehorn HP, et al. Impact of the degree of peri-interventional platelet inhibition after loading with clopidogrel on early clinical outcome of elective coronary stent placement. J Am Coll Cardiol 2006; 48:1742-1750.

3. Sibbing D, Braun S, Morath $\mathrm{T}$, et al. Platelet reactivity after clopidogrel treatment assessed with point-of-care analysis and early drug-eluting stent thrombosis. J Am Coll Cardiol 2009; 53:849-856

4. Wiviott SD, Braunwald E, McCabe $\mathrm{CH}$, et al. Prasugrel versus clopidogrel in patients with acute coronary syndromes. N Engl J Med 2007:357:2001-2015.

5. Wallentin L, Varenhorst C, James S, et al. Prasugrel achieves greater and faster P2Y12receptor-mediated platelet inhibition than clopidogrel due to more efficient generation of its active metabolite in aspirin-treated patients with coronary artery disease. Eur Heart $\mathbf{J}$ 2008; $29: 21-30$

6. Karaźniewicz-Łada M, Danielak D, Burchardt P, Kruszyna L, Komosa A, Lesiak M, Główka F. Clinical pharmacokinetics of clopidogrel and its metabolites in patients with cardiovascular diseases. Clin Pharmacokinet 2014; 53:155-164.

7. Kazui M, Nishiya Y, Ishizuka T, et al. Identification of the human cytochrome P450 enzymes involved in the two oxidative steps in the bioactivation of clopidogrel to its pharmacologically active metabolite. Drug Metab Dispos. 2010;38(1):92-99. doi:10.1124/ dmd.109.029132.

8. Taubert D, Kastrati A, Harlfinger S, Gorchakova O, Lazar A, von Beckerath $\mathrm{N}$, et al. Pharmacokinetics of clopidogrel after administration of a high loading dose. Thromb Haemost 2004; 92: 311-316. her 84, 236-242.

9. Elsinghorst PW. Quantitative determination of clopidogrel and its metabolites in biological samples: a mini-review. J Chromatogr B Analyt Technol Biomed Life Sci 2013; 917-918: 48-52

10. Li X, Liu C, Zhu X, Wei H, et al. Evaluation of Tolerability, Pharmacokinetics and Pharmacodynamics of Vicagrel, a Novel
The results of our study show that the value of aspartate transaminase significantly increases clearance of 2-oxoclopidogrel. None of our patients had liver damage and their ALT values were in the normal range, or slightly above it. Its variability may be attributed to subtle myocardial damage in ACS. Additionally, the available information regarding correlation of liver test and the hemodynamic status is very scarce [18]. Therefore, future studies are required to verify these results.

\section{Conclusion}

Our PPK model for the clearance of 2-oxo-clopidogrel in routinely treated adult patients with ACS showed that the the value of aspartate transaminase and concomitant therapy with digoxin were the main subjects of 2-oxoclopidogrel pharmacokinetic variability.

Acknowledgements: This study was partially financially supported by Grants No 462175007 and No III 41018 given by the Serbian Ministry of Education, Science and Technological Development.
P2Y12 Antagonist, in Healthy Chinese Volunteers. Front Pharmacol 2018; 9:643. doi: 10.3389/fphar.2018.00643. eCollection 2018.

11. Beal SL, Boeckmann AJ, Sheiner LB. NONMEM users guide Parts I-VIII ICON Development Solutions 2013. Ellicott City, MD, USA.

12. Milovanovic JR, Jankovic SM. Population pharmacokinetics of lamotrigine in patients with epilepsy. Int J Clin Pharmacol Ther 2009; 47:752-760.

13. FDA (1999). Guidance for Industry Population Pharmacokinetics. FDA, Rockville. Available at: https://www.fda.gov/downloads/ drugs/guidances/UCM072137.pdf (Last assessed: 10.12.2018.)

14. Yousef AM, Melhem M, Xue B, Arafat T, Reynolds DK, Van Wart SA. Population pharmacokinetic analysis of clopidogrel in healthy Jordanian subjects with emphasis optimal sampling strategy. Biopharm Drug Dispos 2013; 34(4):215-226. doi:10.1002/ bdd. 1839 .

15. Lee J, Hwang Y, Kang W, et al. Population pharmacokinetic/ pharmacodynamic modeling of clopidogrel in Korean healthy volunteers and stroke patients. J Clin Pharmacol 2012; 52(7):985-995. doi:10.1177/0091270011409228

16. Danielak D, Karaźniewicz-Łada M, Komosa A, Burchardt P, Lesiak M, Kruszyna Ł, Graczyk-Szuster A, Główka F. Influence of genetic co-factors on the population pharmacokinetic model for clopidogrel and its active thiol metabolite. Eur $\mathrm{J}$ Clin Pharmacol 2017; 73(12):1623-1632. doi: 10.1007/s00228-0172334-z.

17. Peeters PA, Crijns HJ, Tamminga WJ, Jonkman JH, Dickinson JP, Necciari J. Clopidogrel, a novel antiplatelet agent, and digoxin: absence of pharmacodynamic and pharmacokinetic interaction. Semin Thromb Hemost 1999; 25 Suppl 2:51-54.

18. Van Deursen VM, Damman K, Hillege HL, van Beek AP, van Veld-huisen DJ, Voors AA. Abnormal liver function in relation to hemodynamic profile in heart failure patients. J Card Fail 2010; 16:84-90. 